\title{
The Analysis of Student Metacognition Skill in Solving Rainbow Connection Problem under the Implementation of Research-Based Learning Model
}

\section{Dafik}

Prof, Dean of Faculty of Teacher Training and Education, University of Jember, Jember, Indonesia,d.dafik@unej.ac.id

\section{Bayu Sucianto}

Post Graduate Student of Mathematics Education, Faculty of Teacher Training and Education, University of Jember, Jember, Indonesia, bayusucianto4@gmail.com

\section{Muhtadi Irvan}

Assoc. Prof., Senior Lecturer, Faculty of Teacher Training and Education, University of Jember, Jember, Indonesia, muhtadiirvan@unej.ac.id

\section{Muhammad Abdul Rohim}

Graduate Student of Mathematics Education, Faculty of Teacher Training and Education, University of Jember, Jember, Indonesia

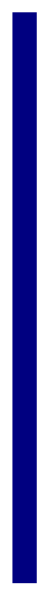

The study aims to investigate the analysis of student metacognition skill in solving the rainbow connection problem under the implementation of the research-based learning model. The method used in this study is a mixed method. The research subjects were the 4th semester of students of higher education consisting of 30 students of experimental class and 45 students of the control class. The instruments of this research are a test, an observation, and an interview. Quantitative method is applied to analyze the difference of student achievement result among two classes, while the qualitative method is applied to analysis the students' metacognitive skills. The results show that there are significant differences between the two classes that applied research-based learning and conventional learning models. The conventional model refers to student-centered learning of Think-Pair- Shares (TPS) model. The statistical result indicates that the (2-tailed) significance of the independent sample t-test in the pre-test was 0.000 or $\alpha \leq 0.05$. It implies that the implementation of RBL significantly affects the students' metacognition skill in solving the rainbow connection problem.

Keywords: metacognitive skill, rainbow connection, research-based learning, think-pairshare 


\section{INTRODUCTION}

Cognitive development is considered to be a determinant of intellectual intelligence (Sutarto, et. al. 2018). Cognitive development is how to manage or organize the cognitive ability in responding to situations or problems. The cognitive aspects cannot be run alone but it needs to be controlled or regulated such that if someone uses his cognitive abilities then it is necessary to be able to determine and regulate what cognitive activity will be used (Hobri, et. al, 2018).

Metacognition refers to the highest level of knowledge that involves the control of the cognitive processes that are involved in learning and consists of two components: (a) cognitive knowledge and (b) cognitive skills. Cognitive knowledge includes (i) declarative, (ii) procedural, and (iii) conditional knowledge, and respects to what individuals know about themselves as cognitive processors. Declarative knowledge relates to the knowledge of oneself as a learner and the factors that affect the performance. Procedural knowledge is knowledge of how to perform certain tasks and conditional knowledge refers to knowing when and why they are using skills or strategies. Cognitive skill refers to how well students can control their learning mechanisms and includes three important skills: (a) planning, which must be done by choosing appropriate strategies for effective performance; (b) monitoring, which deals with someone's awareness on understanding and task performance, and (c) evaluation, which is the assessment of the student's work and their own learning efficiency (Chatzipantelia et. al., 2014).

Table 1

The Indicators of Metacognitive Skills

\begin{tabular}{|c|c|}
\hline Aspects & Indicators \\
\hline Planning & $\begin{array}{l}\text { Read and understand the problem given } \\
\text { Able to predict the completion plan } \\
\text { Able to determine the plan used to solve the problem } \\
\text { Able to know the notation to be used }\end{array}$ \\
\hline Monitoring & $\begin{array}{l}\text { Able to involve prior knowledge in solving the problem } \\
\text { Able to solve the problem in different ways } \\
\text { Doing the right work steps } \\
\text { Checking the correctness of steps } \\
\text { Able to set the result }\end{array}$ \\
\hline Evaluating & $\begin{array}{l}\text { Check the lack of workmanship } \\
\text { Able to determine different ways } \\
\text { Able to apply this method to the problem } \\
\text { Pay attention to the way of working yourself }\end{array}$ \\
\hline
\end{tabular}

Source: Chatzipantelia et. al., (2014)

The students' metacognition skills vary from one student to others as well as student metacognition skills will be different when dealing a different problem. In this study, our problem deals with solving a rainbow connection problem which is a complex problem in discrete mathematics. There is no deterministic algorithm to solve this problem. This problem is even considered to be NP-problem due to its solution process cannot be solved in polynomial times. Therefore, in this study, we implemented research-based 
learning (RBL) model to improve the students' metacognition skill in solving the rainbow connection problem.

Research-Based learning (RBL) is a concept of integrating research results and activities into learning strategy (Sota et. al, 2017). Some researchers found that research-based learning can improve academic achievement, promote learning style, and build new knowledge with oneself (Brew, 2007). Monalisa et. al., (2019) describes that researchbased learning is a learning method using contextual learning, authentic learning, problem-solving, cooperative learning, hands-on \& minds-on learning, and inquiry discovery approach, in which the target of RBL is to encourage the high-level thinking skill of students. The students are not only given information and knowledge but also have to be directed to the higher level of thinking skills, namely creating or communicating. Furthermore, Suntusia, et. al. (2019) also explained that research-based learning has advantages for the students: to improve the learning motivation, encourage skills to perform a certain important task, to improve problem-solving skill especially on complex problems, to make the students more active and able to solve complex problems, to make comfortable learning process, to improve interactivity, and mutual collaboration. It also can develop and practice the communication skill, give students an experience of project organization, provide a learning experience that involves students in learning to gather data and information, to analyze the data according to the data types and at the end disseminating the research results. In addition, Healey et. al. (2014) stressed one of the important factors of RBL is involving and collaboration among the research group (RG) member. Thus, the existence of the research group is absolutely important.

However, the test problem, namely the rainbow connection problem, given to students is a complex problem which needs multi-strategies and techniques to solve it. Once it is mentioned no deterministic algorithm to use it, it implies that this problem is considered to be NP-problem and categorized into a combinatorial problem. The above results related to the implementation of RBL showed by some researchers cannot be implemented directly in this research. The application of the research-based learning model still used an old version of the RBL syntax, It does not meet the combinatorial thinking process in dealing with the rainbow connection problem. Therefore, in this study, we will implement a research-based learning model with new syntax to improve their metacognition skills.

According to Sota, et. al. (2017), in general, RBL consists of three stages 1) Exposure stage, 2) Experience stage, 3) Capstone stage. Exposure stage is gathering information based on inquiry and looking for the literature and research article of specific research of interest. Experience stage is identifying and formulating problems based on literature and experimental experience. Capstone stage is explaining a certain plan or idea in giving problem solution or measurement method or computation. Meanwhile, Suntusia, et. al. (2019) developed the syntax of RBL. They described there seven stages of the RBL syntax, namely: 1) problem posing, 2) developing a problem-solving strategy, 3) data collecting and hypothesis, 4) data analysis, 5) generalizing and conjecturing 6) focused group discussion by the research group member, 7) developing an RBL report. 
Combining the two mentioned RBL models, Tohir et. al. (2019) mixed the syntax and especially in dealing with rainbow connection problems. They develop the following new syntax. First, gathering information to problems arising from research group open problems. Second, develop problem-solving strategies based on experimental experience and literature studies for rainbow connection problem. Third, students are asked to find a special graph, obtain their cardinality. Fourth, the students were encouraged to identify rainbow edge coloring on the special graph. Fifth start to generalize based on each pattern recognition. Sixth, students complete the entire rainbow coloring process to obtain the rainbow connection number. Fifth, the students write an RBL report supervised by the research group members.

The purpose of this study was to determine the effect of research-based learning with the above new syntax on students' metacognition skills compared with the conventional models in solving rainbow connection problems. The conventional model refers to student-centered learning of Think-Pair-Shares (TPS) technique. TPS is a simple group discussion technique, 1) students are divided into several groups, 2) teachers distribute worksheets for each group, 3) students start thinking to solve problems arising from open or unsolved problems of the research group, 4) one group member gathers to synchronize the problem-solving ideas with another group member, and 3) the last, share problem-solving techniques.

In this study we propose the following research question: are there significant differences between the class applied research-based learning and the class applied with Think-Pair- Shares (TPS) model? To answer the research question, we have done some preliminaries study and the results tend to contribute a positive effect. Those we state the following positive hypothesis: there are significant differences between the two classes that applied research-based learning and conventional learning model.

Meanwhile, by rainbow connection, Hasan et. al. (2018) we mean the problem in the following definition.

Definition 1. Let $G$ be a nontrivial connected graph. For $k \in N$, we define a coloring $c$ : $E(G) \rightarrow\{1,2, \ldots, k\}$ of the edges of $G$ such that adjacent edges may be colored the same. A rainbow path connecting two vertices $u$ and $v$ in $G$ is called rainbow $u-v$ path if no two edges of $P$ have the same color. A graph $G$ is said rainbow-connected if for every two vertices $u$ and $v$ of $G$, there exists a rainbow $u-v$ path. In this case, the coloring $c$ is called a rainbow k-coloring of $G$. The minimum $k$ such that $G$ has a rainbow k-coloring is called the rainbow connection number of $G$.

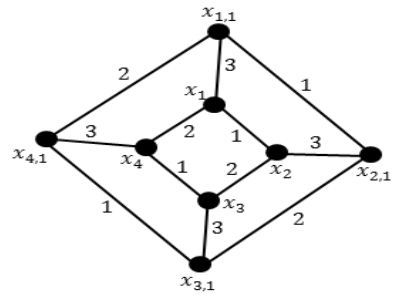

Figure 1

The Example of the Rainbow Coloring of Prism Graph of Order 4. 


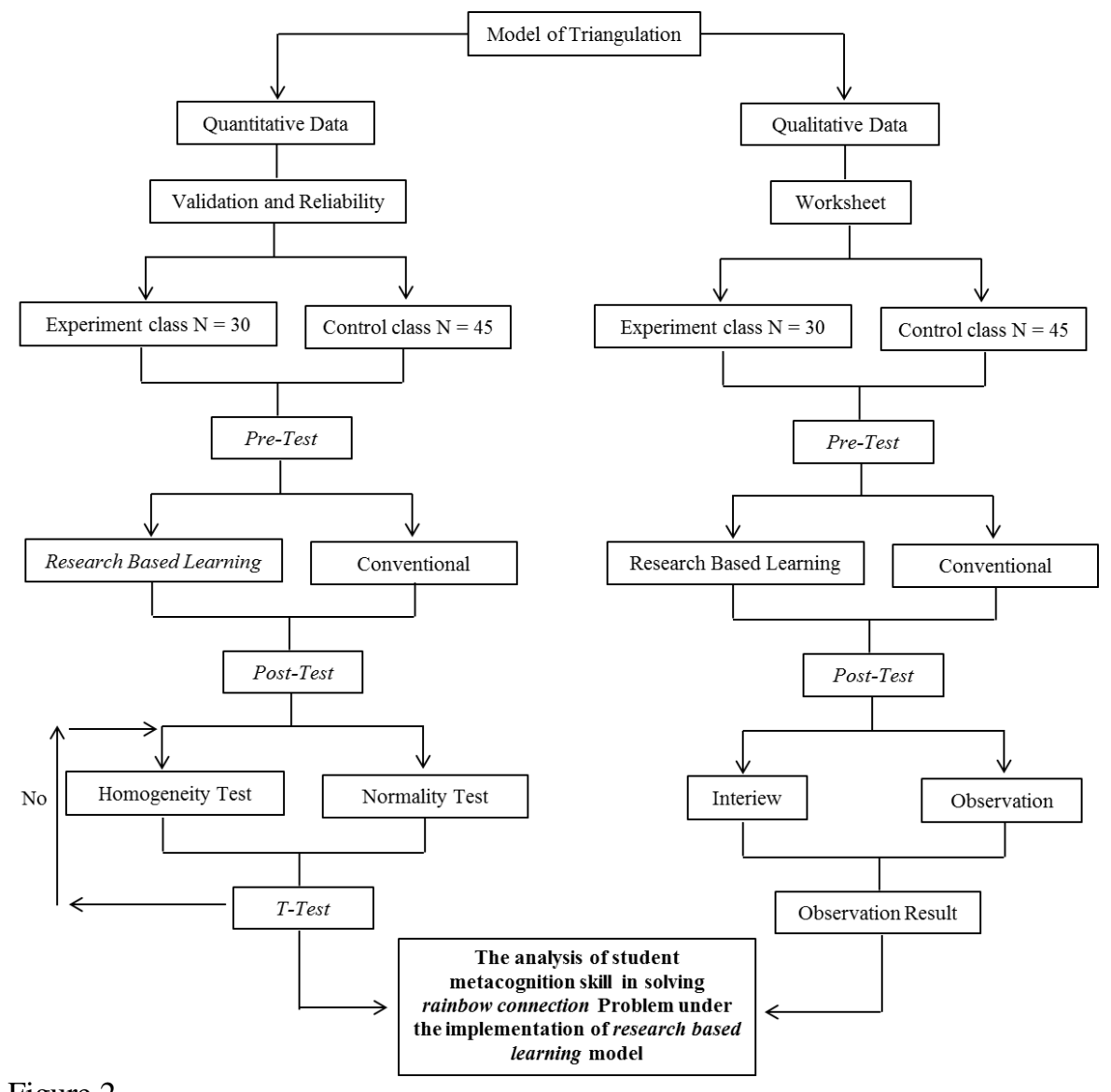

Figure 2

The Model of Triangulation of Mixed Method.

\section{METHOD}

To analyze the student metacognition skill in solving the rainbow connection problem under the implementation of research-based learning model, the researcher used a mixed method. According to Sugiono (2017), a mixed method is the research method that is combining qualitative and quantitative methods. In brief, we can depict the triangulation model in Figure 2. It is seen from the figure; we start the research by determining the two classes of the 4th semester of students of higher education as an experimental class and a control class. Those consisted of 30 students of the experimental class and 45 students of the control class. Further, we developed a pre-test and we gave to both two classes and analyzed the result for the next steps. We did a sequential mixed method, starting from qualitative, quantitative and ended by qualitative. Since the qualitative results gave the result analysis narratively, we convince the result by statistical inferential and then we ended with doing an in-depth interview to some respondents to 
capture their portrait phase of their metacognition thinking skills as well as to know the level of students' metacognition and to convince the improvement of students' metacognition skill. The combination of the two methods also aims to resolve the weaknesses of each method. The following table describes the research design.

Table 2

Pre- and Post-Test Control Group Design

\begin{tabular}{llll}
\hline \multicolumn{1}{c}{ Group } & Pre-test & Treatment & Post-test \\
\hline A (experimental class) $\mathrm{n}=30$ & $\mathrm{O}_{1}$ & $\mathrm{X}$ & $\mathrm{O}_{2}$ \\
$\mathrm{~B}$ (control class) $\mathrm{n}=45$ & $\mathrm{O}_{3}$ & - & $\mathrm{O}_{4}$ \\
\hline
\end{tabular}

\section{Population}

The research subjects were the $4^{\text {th }}$ semester of students of mathematics education department in the FKIP-University of Jember of academic year 2017/2018 consisting of 30 students of the experimental class and 45 students of the control class. The sampling technique used was cluster random sampling that was done by randomly choosing two classes, the first class was the experimental class with the implementation of researchbased learning consisting of 9 males and 21 females, and the second class was control class with the implementation of a think pair share learning model consisting of 12 males and 33 females.

\section{Instruments}

The instruments used in this study were a test, an observation, and an interview. The test instrument is a pre-test and post-test of essay type. The observation instrument used a Linkert scale encompassing into five categories, namely very active (score 5), active (score 4), hesitate (score 3), inactive (score 2), very inactive (score 1), and the last one is an interview completed by an open questionnaire to the student worksheet.

\section{Tasks}

To measure the level of students metacognition skill, it needs an un-procedural problem arising from the research group open problem to be given to the students. The problem is finding a rainbow connection number of a graph. As it was mentioned in the definition, students are required to choose any graph $G$, assign a color $c: E(G) \rightarrow\{1$, $2, \ldots, k\}$ of the edges of $G$ such that adjacent edges may be colored the same and the students can have a rainbow path connecting every two vertices $u$ and $v$ of $G$. Once, they can establish those steps we say that the students have determined a rainbow $k$ coloring of $G$. If $k$ is minimum then the students finally can have a rainbow connection number of $G$. For the illustration of the task, it can be depicted in the following. Given that a ladder graph.

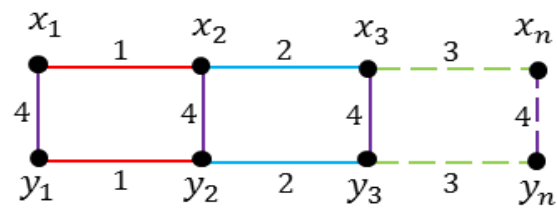

Figure 3

The Example of the Rainbow Coloring of the Ladder Graph of Order 4 
Obtain a rainbow $k$-coloring of a ladder such that every two vertices $u$ and $v$ of ladder has a rainbow path. By considering the diameter of the ladder graph, we start assigning the rainbow colors based on its diameter. The ladder graph has a diameter of 4 , the optimal rainbow color is 4 . Furthermore, by recognizing the pattern, the students should be able to extend to the ladder of order $n$. The last step is finding the function of the color and the rainbow connection number.

\section{Data Collection and Data Analysis}

We gave pre-test and post-test to both experimental and control class. We also apply observation and interview with the subject research. The quantitative analysis was applied by using a $t$-test on the pre-test and post-test results. The qualitative analysis was carried out by using interview and observation instruments. The inferential and descriptive statistics were applied to analyze respectively quantitative and qualitative data. The derived data from the research result were a frequency, mean, and a standard deviation. Moreover, the inferential statistic used independent sample $t$-test to test the difference between the experimental class and the control class (Hilton et al, 2004). The independent samples $t$-test were used to compare the mean score of the two groups with a significance level of 0.05 .

\section{FINDINGS}

Prior to showing our results, we need to test the reliability and validity of our post-test instrument. The following tables show the reliability and validity results of post-test.

Table 3

The Test Result of the Validity Question: Correlations

\begin{tabular}{llllll}
\hline & No_1 & No_2 & No_3 & No_4 & Total \\
\hline No_1 Pearson Correlation & 1 & .591 & .345 & .732 & .862 \\
Sig.(2-tailed) & & .072 & .330 & .061 & .001 \\
N & 30 & 30 & 30 & 30 & 30 \\
\hline No_2 Pearson Correlation & .591 & 1 & .302 & .345 & .719 \\
Sig.(2-tailed) & .072 & & .397 & .330 & .019 \\
N & 30 & 30 & 30 & 30 & 30 \\
\hline No_3 Pearson Correlation & .345 & .302 & 1 & .429 & .681 \\
Sig.(2-tailed) & .330 & .397 & & .217 & .030 \\
N & 30 & 30 & 30 & 30 & 30 \\
\hline No_4 Pearson Correlation & .732 & .345 & .429 & 1 & .817 \\
Sig.(2-tailed) & .061 & .330 & .217 & & .004 \\
N & 30 & 30 & 30 & 30 & 30 \\
\hline Total Pearson Correlation & .862 & .729 & .681 & .817 & 1 \\
Sig.(2-tailed) & .001 & .019 & .030 & .004 & \\
N & 30 & 30 & 30 & 30 & 30 \\
\hline *. Correlation is significant at 0.05 level (2-tailed), $* *$ Correlation is significant at 0.01 level (2-tailed)
\end{tabular}

Based on Table 3, it can be seen that the value $r_{\text {count }}$ of number 1 is 0,862 , number 2 is 0,729 , number 3 is 0,681 , number 4 is 0,817 . All of the items give the value of $r_{\text {count }}$ > $\mathrm{r}_{\text {table }}$ with $\mathrm{N}=30$, thus all items are valid. 
Table 4

The Test Result of the Reliability Question: Reliability Statistics

\begin{tabular}{ll}
\hline Cronbach's Alpha & N of Items \\
\hline .770 & 4 \\
\hline
\end{tabular}

Based on Table 4, it can be seen that the overall reliability value is 0.770 and $\mathrm{r}_{\text {table }}$ of a significance level $5 \%$ with $d k=N-1=29, \mathrm{r}_{\text {table }}=0.666$. Therefore $\mathrm{r}_{\text {count }}>\mathrm{r}_{\text {table }}$. It concludes that the instrument items are reliable.

Furthermore, we will show the distribution of students' metacognition skills of both control and experimental classes based on their pre-test result as follows.

The percentage of metacognition skills of the control class

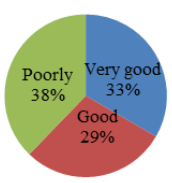

The metacognition skills of the control class

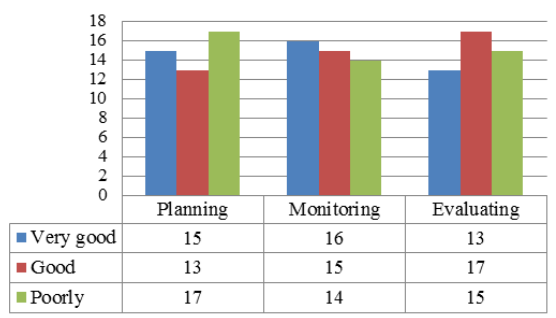

Figure 5

The Distribution of Students' Metacognition Skills of the Control Class based on PreTest Result

The percentage of metacognition skill of the eksperimental class

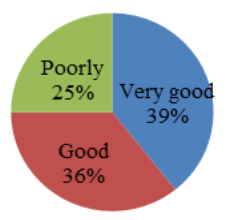

Figure 6

The Distribution of Student Metacognition Skills of the Experimental Class based on Pre-Test Result

Based on the results of the pre-test analysis between the two classes, it can be seen both classes have the same variance. The results showed the metacognition skills of the control class gaining very good is $33 \%$, good is $29 \%$, and poor is $38 \%$, while for the experimental class gaining very good is $39 \%$, good is $36 \%$, and poor is $25 \%$. The results of both classes can be seen in Figure 5 and Figure 6. By this distribution, it will help our knowledge to interpret the significant affection of the research-based learning to the students' metacognition skill in solving the rainbow connection problem. 
Now, we will analysis the homogeneity test and normality test, and finally, we will analyze the mean difference by using the independent sample $t$-test.

Table 5

The Analysis of the Homogeneity of Pre-Test

\begin{tabular}{llll}
\hline \multicolumn{4}{c}{ Test of Homogeneity of Variances } \\
\hline Class & df1 & df2 & Sig. \\
\hline Levene Statistic & 1 & 58 & .186 \\
\hline 1.793 & & & \\
\hline
\end{tabular}

Table 5 shows the results of the homogeneity test of the pre-test, the value (Sig.) in the analysis of homogeneity variances table test is 0.186 . Thus, it can be concluded that the assumption of homogeneity of variance is satisfied. The obtained significance value is more than 0.05 , it implies the data shows homogeneous variance.

Table 6

The Result of Mean Scores of Pre-Test between Control and Experimental Classes

\begin{tabular}{lllll}
\hline Group & N & Mean & Std. Deviation & Std. Error Mean \\
\hline The Pre-test score of Control class & 45 & 62,0000 & 3,54625 & .64745 \\
The Pre-test score of Experimental class & 30 & 63,1000 & 2,92326 & .43577 \\
\hline
\end{tabular}

The liability of the pre-test result distribution was 0.05 . The mean score in control class is 62.0000 ( $\mathrm{SD}=3,54625)$ while in experimental class is $63,1000(\mathrm{SD}=2,92326)$. The difference between pre-test achievement in control class and experimental class score of 2 groups was $[\mathrm{t}(75)=0.130, \mathrm{p}>0.05]$, which shows the difference is not significant.

Table 7

The Comparison of Pre-Test Score of Experimental Class and Control Class Score Using Independent Sample T-Test

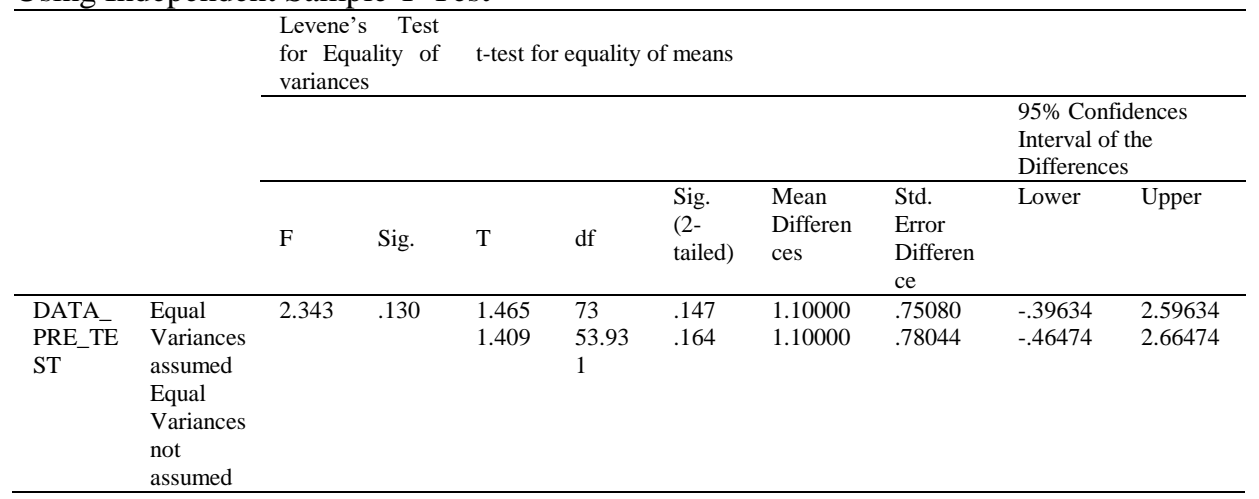

Table 7 also shows that the result of $t$-test indicates the sig. (2-tailed) of independent sample $t$-test of pre-test is 0.147 ( $\mathrm{p}>0,05)$, thus it is not significant. It implies the two classes are homogeneous in term of student achievement test.

Now it is time to analyze the result on post-test by using the inferential statistic. We start by analyzing the normality test. 
Table 8

The Analysis of the Normality Test of Both Class for the Post-Test

\begin{tabular}{|c|c|c|c|}
\hline \multicolumn{4}{|c|}{ One-Sample Kolmogorov-Smirnov Test } \\
\hline & & $\begin{array}{l}\text { Post Test (Control } \\
\text { Class) }\end{array}$ & $\begin{array}{l}\text { Post Test } \\
\text { (Experimental Class) }\end{array}$ \\
\hline $\mathrm{N}$ & & 45 & 30 \\
\hline \multirow[t]{2}{*}{ Normal Parameters ${ }^{\mathrm{a}, \mathrm{b}}$} & Mean & 71.3333 & 80.3333 \\
\hline & Std. Deviation & 5.24130 & 3.69840 \\
\hline \multirow[t]{3}{*}{ Most Extreme Differences } & Absolute & .191 & .236 \\
\hline & Positive & .187 & .236 \\
\hline & Negative & -.191 & -.231 \\
\hline Kolmogorov-Smirnov Z & & 1.047 & 1.292 \\
\hline $\begin{array}{l}\text { Asymp. Sig. (2-tailed) } \\
\text { a. Test distribution is Normal. } \\
\text { b. Calculated from data. }\end{array}$ & & .223 & .071 \\
\hline
\end{tabular}

The results of the normality test of each group, it was obtained the significance value are the control is 0.223 , the experimental is 0.71 . The significance value of the two classes is greater than the value of $\alpha(0.05)$, meaning that the two classes of research samples are normally distributed.

Table 8

The Result of Mean Scores of Post-Test between Control and Experimental Classes

\begin{tabular}{lllll}
\hline Group & $\mathrm{N}$ & Mean & Std. Deviation & Std. Error Mean \\
\hline The Post-test score of Control class & 45 & 68.9667 & 3,93467 & .71837 \\
The Post-test score of Experimental class & 30 & 70,0000 & 3,69274 & .55048 \\
\hline
\end{tabular}

Table 8 present the post-test result of control class, it is written at 68.9667 (SD = $3,93467)$, while the experimental class, it is written at 70,0000 ( $\mathrm{SD}=3,69274)$. Table 9 also shows there is significant difference between the two classes as indicated by [ $\mathrm{t}(75)$ $=0.021, \mathrm{p}<0.05]$.

Table 9

The Comparison of the Post-Test Score of Experimental Class and Control Class Score Using Independent Sample T-Test

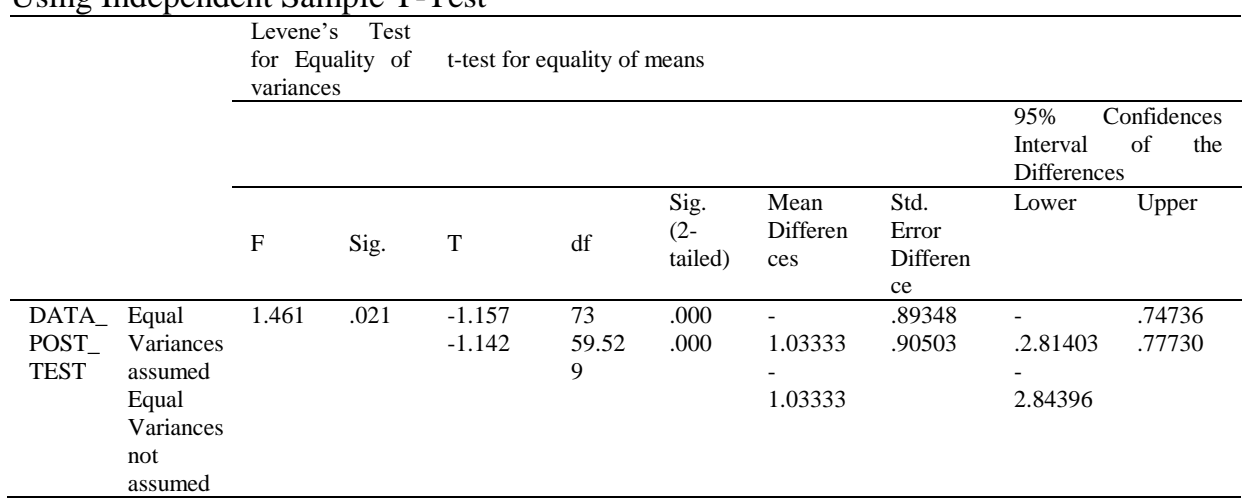


Table 9 shows that the result of $t$-test indicates sig. (2-tailed) of independent sample $t$ test of post-test is $0.00(\mathrm{p}=<0,05)$, thus it is significant. It implies that the implementation of RBL significantly affected the students' metacognition skill in solving the rainbow connection problem.

The percentage of metacognition skills of the control class

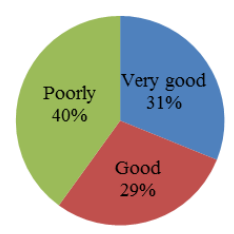

The metacognition skills of the control class

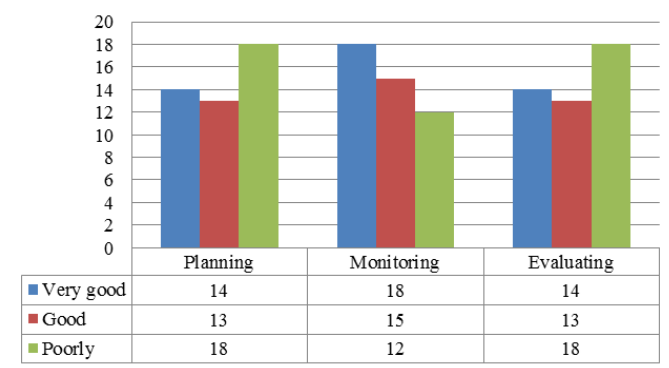

Figure 7

The Distribution of Student Metacognition Skills in the Control Class based on the PostTest Result

Furthermore, based on the post-test result, it showed the metacognition skills of the control class is very good of $31 \%$, good of $29 \%$, and poor of $40 \%$, while for the experimental class showed very good of $67 \%$, good of $23 \%$, and poor of $10 \%$. The results of both classes can be seen in Figure 7 and Figure 8. It can be seen that the experimental class is superior to the control class.

The percentage of metacognition skill of the eksperimental class

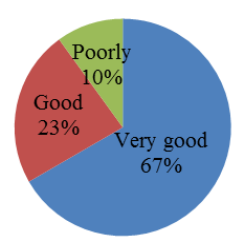

Figure 8

The Distribution of Student Metacognition Skills in the Experimental Class based on the Post-Test Result

To convince our result, we did an observation of all students activities under the implementation of research-based learning. The observation items were done by 10 observers, and it was assessed by using a Linkert scale encompassing very active (score 5 ), active (score 4), hesitate (score 3), inactive (score 2), very inactive (score 1). The observation result can be shown in the following chart. 

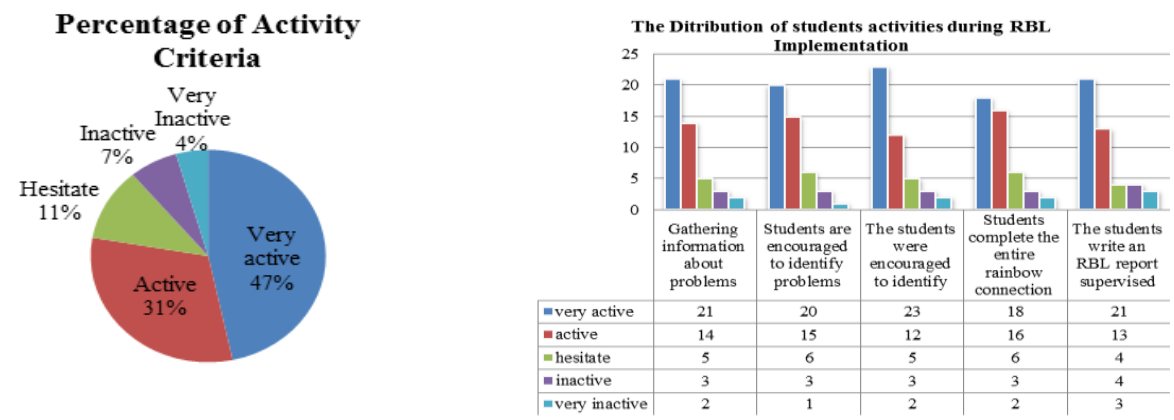

Figure 9

The Distribution of the Observation Result on the Students' Activities under the Implementation of Research Based-Learning

Based on figure 9, the student involved in the observation was 45 students. It was found that the highest score of observation criteria reached $47 \%$. It indicates that, during RBL implementation, students are strongly active to engage with the solving the problem, and $31 \%$ of students reach the active level, and the rest of $22 \%$ are on hesitate, inactive and very inactive levels. It can be concluded that RBL can work well in the learning process on solving rainbow connection problem, it is able to improve the students' metacognition skills.

Furthermore, as a completion of the mix-method, we also did an observation of the student's worksheet results on post-test. The followings are the example of the student S05.

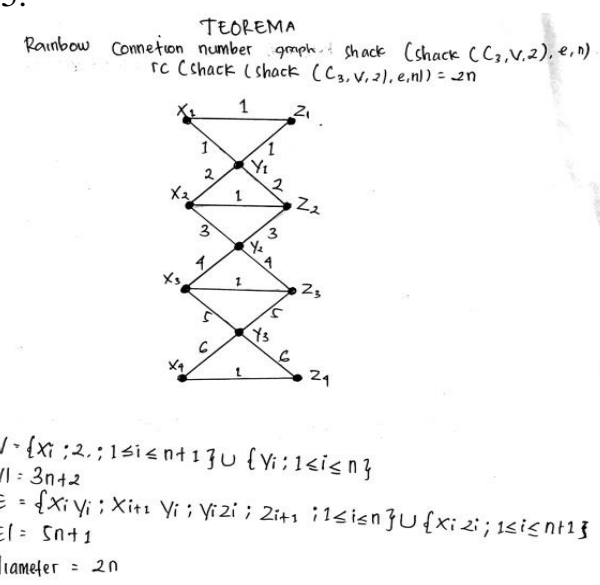

Figure 10

The Worksheet Result of Student S05 under the Implementation of RB 


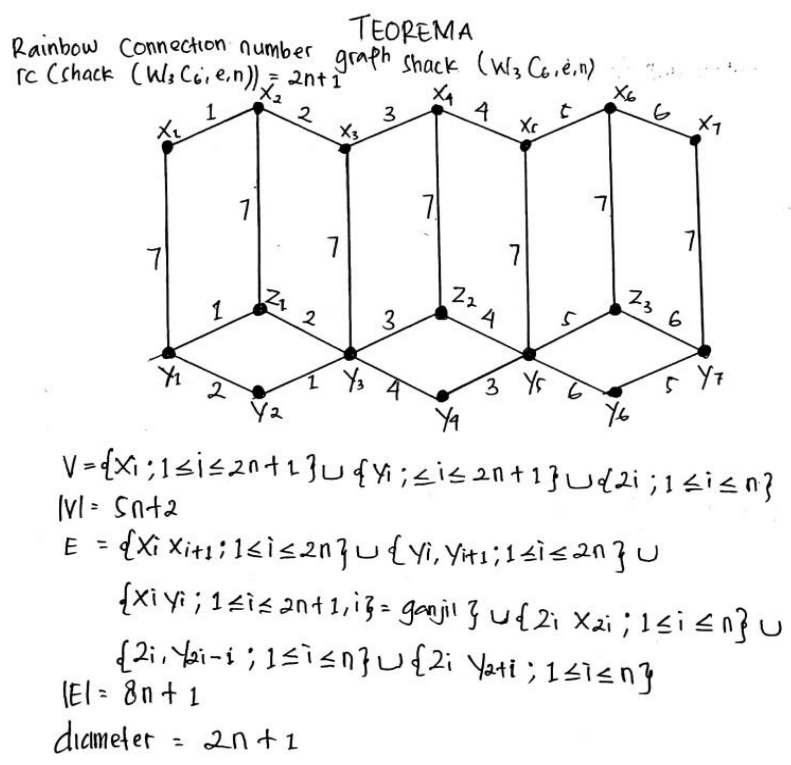

Figure 11

The Worksheet Result of Student S15 under the Implementation of RBL

In this step, student S05 assigns a rainbow coloring on $\left.\operatorname{shack}\left(C_{3}, v, 2\right), e, n=3\right)$ as it is written above. The student starts assigning the colors 1 of the first cycle, and continue to assign colors $2, \ldots, 6$. It has been obtained the optimal color, namely the rainbow connection number of 6 . The students then continue to obtain the cardinality of the graph in general i.e. $\left.\operatorname{shack}\left(C_{3}, v, 2\right), e, n\right)$. It gives the order of $\mid V(\operatorname{shack}(C 3, v, 2), e, n)) \mid=3 n+2$ and size of $\left.\mid E\left(\operatorname{shack}\left(C_{3}, v, 2\right), e, n\right)\right) \mid=2 n$. By a different way, the student S15 assigns a rainbow coloring on a different graph, namely $\left.\operatorname{shack}\left(W_{3} C_{6}, e, n=3\right)\right)$ as it is written above. The student starts assigning the colors 1 of the first subgraph $\mathrm{W}_{3} \mathrm{C}_{6}$, and continue to assign colors $2, \ldots, 7$. It has been obtained the optimal color, namely the rainbow connection number of 7 . The students then continue to obtain the cardinality of the graph in general i.e. $\operatorname{shack}\left(W_{3} C_{6}, e, n\right)$. It gives the order of $\left|V\left(\operatorname{shack}\left(W_{3} C_{6}, e, n\right)\right)\right|=5 n+2$ and size of $\left|\mathrm{E}\left(\operatorname{shack}\left(W_{3} C_{6}, \mathrm{e}, \mathrm{n}\right)\right)\right|=8 \mathrm{n}+1$. Since the rainbow connection number attains the diameter as the lower bound, thus $\left.r c\left(\operatorname{shack}\left(C_{3}, v, 2\right), e, n\right)\right)=2 n$. It happens also for the graph $\left.\left.\operatorname{shack}\left(W_{3} C_{6}, v, 2\right), e, n\right)\right)$. Since the rainbow connection number attains the diameter as the lower bound, thus $\left.r c\left(\operatorname{shack}\left(W_{3} C_{6}, v, 2\right), e, n\right)\right)=2 n+1$.

The students' work were continued by constructing the color function to prove the rainbow connection number of $\operatorname{shack}(C 3, v, 2), e, n)$ and $\operatorname{shack}(W 3 C 6, e, n)$. Based on the RBL syntax, students entered to the third and fourth steps, namely the students were encouraged to identify rainbow edge coloring on a special graph and start to generalize based on each pattern recognition and to complete the entire rainbow coloring process to obtain the rainbow connection number. The students S05 and S15 identified the 
diameter of the graphs, and extend the color to the graphs of order $n$. Once they have found the diameter, they used it as a lower bound of the rainbow connection number. To find the upper bound they should extend the color up to the graphs of order $n$. The following, we helped the student S05 to extend and construct the color function.

Define a color $\left.f: E\left(\operatorname{shack}\left(C_{3}, v, 2\right), e, n\right)\right) \rightarrow\{1,2, \ldots, k\}$. The color function can be constructed as follows.

$$
f\{e\}=\left\{\begin{array}{l}
1, \text { for } e=x_{i} z_{i} \text { and } 1 \leq i \leq n+1 \\
2 i-1, \text { for } e=x_{i} y_{i}=y_{i} z_{i} \text { and } 1 \leq i \leq n \\
2 i, \text { for } e=x_{i+1} y_{i} \text { and } 1 \leq i \leq n
\end{array}\right.
$$

It is easy to see that $\left.f: E\left(\operatorname{shack}\left(C_{3}, v, 2\right), e, n\right)\right) \rightarrow\{1,2, \ldots, 2 n\}$. Thus the biggest number of the color of the graph $\left.\operatorname{shack}\left(C_{3}, v, 2\right), e, n\right)$ is $2 n$. Therefore the upper bound of the rainbow connection number is $2 n$. Combining the two facts, the first the rainbow connection number attains the diameter as the lower bound, and the biggest number of the color is $2 n$, thus $\left.r c\left(\operatorname{shack}\left(C_{3}, v, 2\right), e, n\right)\right)=2 n$. The same way with the graph belongs to the student $\mathrm{S} 15$. It also attains the diameter as the lower bound, thus $\left.\operatorname{rc}\left(\operatorname{shack}\left(W_{3} C_{6}, v, 2\right), e, n\right)\right)=2 n+1$.

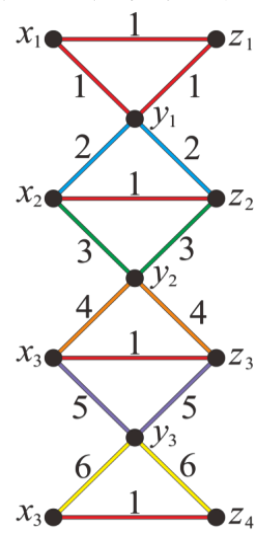

(a)

Figure 12

The Generalization Process to Finding the Rainbow Connection Number of the Graph Shack $\left.\left(C_{3}, v, 2\right), e, n\right)$.

To find out the students' perception of the implementation of research-based learning, the researcher performed an interview on student S05. The student is selected due to this student has gained high criteria of metacognition skill. The data obtained through the interview process was transcripted below.
Researcher
- Did you understand well what it is asked in the worksheet?
Student
- Yes, I did. But it is hard to develop a well-defined graph.
Researcher
- How can you start to develop a strategy to solve the problem? 
Student : I am trying to browse by using Google search and find the special

graph families, also download some articles by using ScienceDirect

Researcher : When you have found the graph families how do you assign rainbow coloring?

Student : I assign the rainbow colors by starting with the smaller order, check the optimal color, if it is the smallest one then I recognize the pattern and increase the order and continue the color such that I can generalize the color on the graph of order $n$.

Researcher : How do you guarantee that the color is a minimum one?

Student : I try the color more than one, at least three times. When I have understood the pattern, furthermore I continue the color for the larger order and observe the number of colors, if it remains the same then I decide to consider that it is the smallest one.

Researcher : How do you then obtain the rainbow connection number?

Student : According to the obtained phase that I have learned, I obtain the diameter first of the graph of order $n$. I confirm the minimal obtained color to the obtained diameter. If it is so, then I decide that I have found the rainbow connection number.

Researcher : Did you develop the rainbow color function as well? Do you know what is the benefit of doing that?

Student : Yes, it is very important. Firstly, to ensure that the obtained color is extendable, secondly, we can make sure the smallest one from the color function.

Researcher : Did you work alone? Has your friend helped you a lot?

Student : I solve this problem in a group, otherwise, it is too hard to solve by myself. My friend and I are working together to solve this problem

From the above interview, we can depict of the student metacognition process in the following phase portrait. 


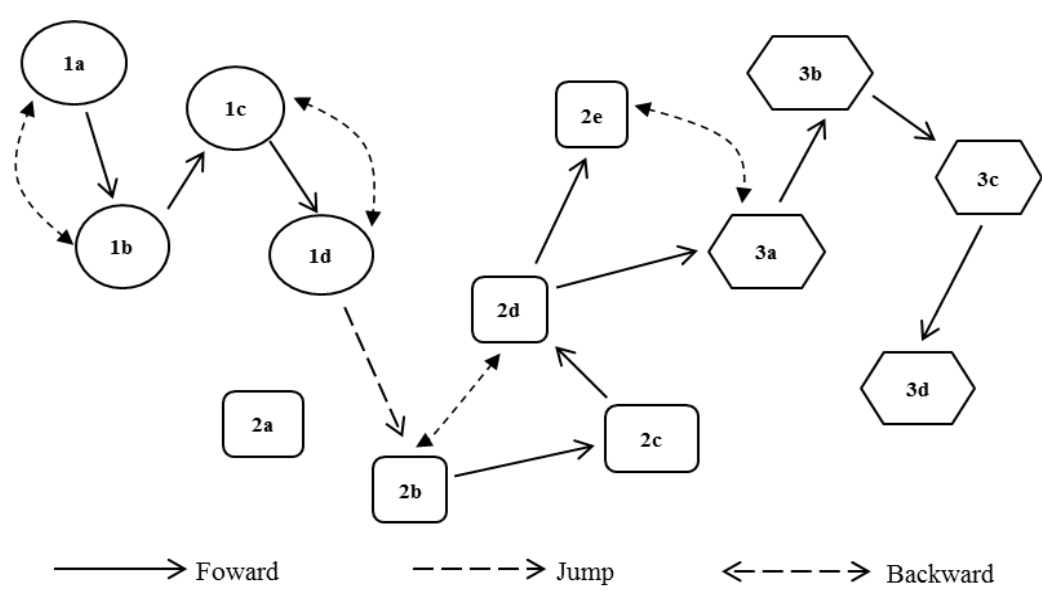

Figure 13

The Phase Portrait Student Metacognition Process of the High Criteria of Metacognition Skill

\section{DISCUSSION}

This research was conducted to analyze the implementation of research-based learning to improve student metacognition skills in solving the rainbow connection problem. The findings of this study indicate that the implementation of research-based learning has a significant influence on the improvement of students metacognitive skills. It showed the metacognition skills of the control class is very good of $31 \%$, good of $29 \%$, and poor of $40 \%$, while for the experimental class showed very good of $67 \%$, good of $23 \%$, and poor of $10 \%$. From these results, the students, in the experimental class, showed their metacognitive skills higher compared to the control class.

This result in line with Suntusia, et.al (2019) results. Since the steps of this learning model stress to the student-centered learning and under the lecturer supervision, students are encouraged to identify problems and develop problem-solving strategies based on experimental experience and literature studies, it implies that the student's mind is always consistently active in solving a given problem. Furthermore, this study was in line with the study conducted by Landine et. al. (1998) showing that the awareness of metacognition impacts on academic achievement. This indicates that when we can improve the student metacognition skills, it will imply to the improvement of students academic achievement.

The research-based learning also provides a different learning experience which can develop student metacognition skills. Students were challenged to solve and achieve problem-solving, and finally gains a depth understanding and knowledge (Schapper et.al., 2010). It also contributes to the existence of positive students activities under RBL implementation, see Patrick (2012). The data obtained through the observation process revealed that students gave a positive response. The highest score of observation criteria reached $47 \%$. It indicates that, during RBL implementation, students are strongly 
active to engage with the solving the problem, and $31 \%$ of students reach the active level, and the rest of $22 \%$ are hesitate, inactive and very inactive levels. It can be concluded that RBL can contribute a positive learning process on solving the rainbow connection problem. Finally, its implementation can improve the students' metacognition skills.

\section{CONCLUSION}

We have studied the implementation of research-based learning to improve student metacognition skills in solving the rainbow connection problem. Based on the research result the RBL has a significant effect on students' metacognition skills. Students, in the experimental class, showed their metacognition skills higher compared with the control class. Finally, we can claim that the RBL implementation can improve the students' metacognition skills. However, solving a rainbow coloring problem is considered to be a hard problem, even it is classified as an NP-hard. There does not exist a fixed algorithm to solve it. Persistent motivation to the students such that the students possess an active mind on is the only way to find the solution. Therefore, we suggest the other researchers do research on students conjecturing skills under the implementation of research basedlearning.

\section{ACKNOWLEDGMENT}

I gratefully acknowledge the support from CEREBEL Research Groups, FKIPUniversity of Jember Indonesia of the year 2019.

\section{REFERENCES}

Brew A., (2010). A imperatives and challenges in integrating teaching and research. Higher Education Research \& Development, 29(2), 139-150.

Chatzipantelia, A., Grammatikopoulos, V., \& Gregoriadis, A., (2014). Development and evaluation of metacognition in early childhood education. Early Child Development and Care. 184(8), 1223-1232.

Healey, M., Jenkins, A., \& Lea, J., (2014). developing research-based curricula in college based higher education. New York: The Higher Education Academy.

Hobri, Dafik, \& Hossain, A. (2018). The implementation of learning together in improving student' mathematical performance. International Journal of instruction, 11(2), 483-496.

Hasan, M. S., Slamin, Dafik, Agustin, I. H., \& Alfarisi, R. (2018). On the total rainbow connection of the wheel related graphs. Journal of Physics: Conference Series, 1008(1), 012054 .

Landine J., \& Stewart, J., (1998). relationship between metacognition, motivation, locus of control, self-efficacy, and academic achievement. Canadian Journal of Counselling, 32(3), 200-2012. 
Monalisa, L. A., Dafik, Hastuti, Y., Hussen, S., \& Oktavianingtyas, E. (2019). The implementation of research-based learning in developing the students mathematical generalization thinking skills in solving a paving blocks design problem. IOP: Earth and Environmental Science, 243, 012168.

Patrick, G. (2012). Research-based learning: Teaching development through field schools. Journal of Geography in Higher Education, 36(3), 329-339.

Schapper, J., \& Mayson, E. S. (2010). Research-led teaching: Moving from a fractured engagement to a marriage of convenience. Higher Education Research \& Development, 29(2), 641-651.

Sota, C., \& Karl, P. (2017). The effectiveness of research-based learning among master degree student for promotion and preventable disease, Faculty of Public Health, Khon Kaen University, Thailand. International Conference on intercultural Education, Health and ICT for a Transcultural Word, EDUHEM, 19(4), 725-737.

Suntusia, Dafik, \& Hobri. (2019). The effectiveness of research-based learning in improving students' achievement in solving two-dimensional arithmetic sequence problem. International Journal of Instruction, 12(1), 17-32.

Sutarto, S., Nusantara, T., Subanji, S., Dwi Hastuti, I., \& Dafik, D., (2018). Global conjecturing process in pattern generalization problem. Journal of Physics: Conference Series, $1008(1), 012060$.

Sugiono, (2017). The mixed method of research. Bandung, Indonesia: AlfaBeta.

Tohir, M., Abidin, Z., Dafik, D., \& Hobri. (2018). students creative thinking skills in solving two-dimensional arithmetic series through research-based learning. Journal of Physics: Conference Series, 1008(1), 012072. 